\title{
DIE LOOPBAANPATRONE VAN SUID-AFRIKAANSE BESTUURDERS
}

\author{
A M G SCHREUDER
}

\author{
Departement Bedryfsielkunde
}

Universiteit van Suid-Afrika

\section{SUMMARY}

Career paths of South African Managers. The changing nature of work results in upward mobility within organisations becoming increasingly limited. This requires individuals to rethink their careers. An important prerequisite for this is adequate self-knowledge. Preferred career paths are often related to the "career culture" of an organisation, which is often not aligned with individual motives and needs. The aim of this study was to determine the match between career preferences and career motives. The results on the whole indicate a poor match between these constructs. Recommendations are made on the basis of these findings.

\section{OPSOMMING}

Die veranderende aard van werk veroorsaak dat opwaartse mobiliteit in organisasies meer beperk raak. Dit verg dat individue opnuut oor hulle loopbane sal moet besin. ' $n$ Belangrike voorvereiste hiervoor is voldoende selfkennis. Die loopbaanpad wat individue verkies hou dikwels verband met die loopbaankultuur van 'n organisasie en is nie altyd in ooreenstemming met hulle eie motiewe en behoeftes nie. Die doel van hierdie studie was om te bepaal in watter mate daar' $n$ passing is tussen die respondente se loopbaanvoorkeure en hulle loopbaanmotiewe. Die resultate dui oor die algemeen op 'n swak passing. Aanbevelings word op grond van die bevindinge gemaak.

Organisasies is wêreldwyd aan die verander, veral ten opsigte van organisasiestrukture, arbeidsamestelling, vergoedingstelsels, dienskontrakte, tegnologie en inligting. Organisasies word al meer gekenmerk deur buigsaamheid wat betref grootte en funksies van die arbeidsmag en bemagtinging van werknemers; daar is 'n neiging tot selfbestuur, platter strukture, minder personeel (veral middelbestuurders), deelneming aan die leerprosesse, spanwerk, gedeelde waardes, uitkontraktering van dienste; minder beheer deur bestuur; daar word gestreef na spesialiskennis, multivaardigheid en minder omskrewe poste, en die fokus val reëlreg op die kliënt (Davis, 1995; Drucker, 1988; Cascio, 1995(b); Handy, 1995; Harris, 1993; Kanter, 1990; Sadler, 1991; Schein, 1993; Senge, 1990; Uys, 1993).

Die eerste demokratiese verkiesing in April 1994 het onder andere tot die hersamestelling van die Suid-Afrikaanse arbeidsmag gelei. Vrouens en sekere bevolkingsgroepe wat voorheen grotendeels daarvan uitgesluit was, is nou meer deel van die arbeidsmag. Dit is hoofsaaklik as gevolg van regstellende aksie. Die Buro vir Marknavorsing aan Unisa voorspel dat in 2011, in teenstelling met 1991 , swartes $77,3 \%$ van die werksmag sal uitmaak teenoor $68,8 \%$, blankes $11,8 \%$ teenoor $19,8 \%$, kleurlinge $8,5 \%$ teenoor $10,3 \%$ en Asiate $2,4 \%$ teenoor $2,9 \%$. Daar word ook verwag dat die vroulike werknemers gemiddeld met $3,2 \%$ per jaar sal groei teenoor die $2,4 \%$ van die mans (Sadie \& Martins, 1994). By Unisa is tans $54 \%$ van die studente vroulik, wat hierdie voorspellings bevestig.

Die herstrukturering van organisasies wat dikwels met personeelvermindering gepaard gaan, is tans ' $n$ wêreldwye verskynsel. In 1993 het die VSA 615,186 afleggings - 'n nuwe rekord aangekondig. In die eerste helfte van 1994 was dit 300 000, wat ongeveer $17 \%$ meer was as in die ooreenstemmende tydperk in 1993 (Cascio, 1995(a)). Die getal werknemers in Suid-Afrikaanse organisasies het tussen 1989 en 1994 met ongeveer 20\% verminder - 169000 poste is afgeskaf en ongeveer 800000 werknemers is daardeur geraak (CSD Bulletin, 1994). 'n Opname het getoon dat ongeveer $45 \%$ van Suid-Afrikaanse organisasies verwag om hulle werknemers te verminder (Sake-Beeld, 22 Januarie 1996). Inligting dui daarop dat ongeveer 100000 staatsdiensamptenare hulle werk in die volgende drie jaar kan verloor

Versocke wir herdrukke moct gcrig word aan AMG Schreuder Departement Beroeke vir herdrukke moct gerig word aan AMG Schreuder,
Herstrukturering het dikwels ' $n$ vermindering in hiërargiese vlakke tot gevolg. Harris (1993) noem dat sommige groot organisasies hulle vlakke reeds met ongeveer $50 \%$ verminder het. Drucker het in 1988 al voorspel dat 'n tipiese groot organisasie teen die jaar 2000 naastenby die helfte van sy huidige bestuursvlakke en een derde van sy aantal bestuurders sal hê. Volgens Handy (1995) is die meeste organisasies in Engeland se mikpunt slegs vier hiërargiese vlakke. 'n Opname onder Suid-Afrikaanse organisasies het getoon dat die meeste respondente besig is om hul organisasievlakke te verminder (Mastrantonis \& Nel, 1995)

Hierdie veranderinge behoort noodwendig implikasies vir loopbaanbeplanning in organisasies te hê, sodat loopbaansukses waarskynlik herdefinieer moet word. Dit sal nie meer aan konstante progressie of die bemeestering van 'n spesifieke werk gemeet kan word nie, maar eerder aan die mate waarin die individu se loopbaanbehoeftes bevredig word. Loopbane raak meer siklies van aard en laterale skuiwe, eerder as opwaartse skuiwe, raak aan die orde van die dag (Hall \& Mirvis, 1995). Individue sal moet opgevoed word om af te sien van gereelde bevorderings as die belangrikste kriteria van sukses, aangesien dit nie meer so vrylik gaan voorkom nie.

Werksekuriteit word deur die veranderings bedreig deurdat daar daagliks poste afgeskaf word, met die gevolg dat lojale, getroue werkers hulle werk verloor. In die nuwe era val die klem eerder op indiensneembaarheid as op indiensneming (Kanter, 1990). Sekuriteit is dus eerder op vaardighede as op strukture en postitels gebaseer (Weick \& Berlinger, 1989). Die persoon wat voortdurend leer en oor die kundigheid beskik waaraan daar ' $n$ behoefte in die arbeidsmark is, sal in ' $n$ groot mate van 'n werk verseker wees. 'n Loopbaan vandag beteken dus 'n verbintenis tot leer en die voortdurende opgradering van vaardighede.

Aangesien die motiveringswaarde van bevordering nie meer so hoog is nie, raak posverryking, indiensneembaarheid en die skep van geleenthede vir werknemers om die vaardighede te ontwikkel wat nodig is om na hulself om te sien, nog belangriker (Noer, 1993). Dit impliseer dat individue meer as ooit tevore selfverantwoordelikheid vir hulle loopbane sal moet aanvaar. 'n Belangrike voorvereiste hiervoor is voldoende selfkennis.

Die literatuur oor loopbane die afgelope jare het getoon dat individue dikwels 'n gebrek aan kennis het wat betref hulle eie voorkeure, waardes, behoeftes en motiewe. Sulke individue is 
swak toegerus om loopbaanbesluite te kan neem. Selfkennis in 'n veranderende omgewing is nog méér noodsaaklik om individue in staat te stel om beter keuses te kan maak. Die loopbaanpatroonmodel van Driver \& Brousseau (1990) kan moontlik 'n verdere bydrae in dié opsig lewer. Die model dui die teenstrydigheid aan wat daar bestaan tussen die loopbaanpad wat individue dikwels kies, teenoor dié loopbaan wat waarlik begeer word. Deur hierdie teenstrydigheid uit die weg te ruim kan individue volgens hulle loopbaanbehoeftes geplaas word en die druk met betrekking tot bevorderings sodoende verlig word.

Die model beskryf vier verskillende tipes loopbaanpatrone, elk met ' $n$ unieke konseptualisering van loopbaansukses (Brousseau \& Driver, 1994). Elk van die loopbaanpatrone is op onderliggende motiewe gebaseer (Brousseau, 1990; Brousseau \& Driver, 1994). Die verskillende loopbaanpatrone word vervolgens bespreek.

\section{- Die lineêre loopbaanpatroon}

Hierdie patroon verteenwoordig die tradisionele siening van loopbaansukses. Individue wat hiermee assosieer, verkies om vinnig in die hiërargie van die organisasie op te beweeg. In bestuur beteken dit dat die suksesvolste loopbaan daardie een is waarin die vinnigste met die bestuurshiërargie opbeweeg word na poste met meer verantwoordelikhede en gesag. Hierdie siening is redelik algemeen onder Suid-Afrikaanse werknemers.

\section{- Die deskundige loopbaanpatroon}

Hierdie patroon verskil opmerklik van die lineêre patroon. Volgens hierdie perspektief beteken 'n suksesvolle loopbaan 'n lewenslange verbintenis tot ' $n$ spesialiteitsveld of beroepsgroep, byvoorbeeld prokureur of mediese dokter. Individue in bestuur, wat dié patroon verkies, sal byvoorbeeld in 'n staffunksie aangestel word en vorder totdat hulle uiteindelik die hoof daarvan is. By akademici, waar hierdie loopbaanpatroon veral voorkom, word individue byvoorbeeld as lektore aangestel en vorder hulle tot professore. Alhoewel daar progressie plaasvind, bly individue steeds tot hulle kundigheidsveld verbind.

\section{- Die spiraalvormige loopbaanpatroon}

Die spiraalvormige loopbaanpatroon is meer ongewoon as bogenoemde twee patrone. Volgens dié patroon is die beste loopbaanpad dié een waar periodiek tussen beroepe, spesialiteitsvelde of dissiplines gewissel word. So 'n verwisseling vind gewoonlik elke sewe tot tien jaar plaas. Die ideaal is om na 'n verbandhoudende veld te beweeg en verworwe kennis en vaardighede in die nuwe veld te gebruik (byvoorbeeld van ingenieurswese of navorsing na produkontwikkeling).

- Die kortstondige loopbaanpatroon

Van die vier loopbaanpatrone is hierdie patroon die mins tradisionele patroon. As 'n patroon kan dit as "consistent inconsistency" beskryf word. Dit is nie-permanent van aard en van korte duur. Hiervolgens verander ' $n$ individu ongeveer elke drie tot vyf jaar van loopbaan of werk na 'n heeltemal nieverbandhoudende veld of werk. Individue wat dié patroon verkies, beskou hulself dikwels as iemand sonder 'n loopbaan.

\section{PASSING TUSSEN LOOPBAANPATRONE EN PER- SOONLIKE MOTIEWE}

Bestuursloopbane bied geleenthede om verskillende werksverwante behoeftes te bevredig. So behoort individue wat in bogenoemde loopbaanpatrone (lineêr, deskundig, spiraalvormig en kortstondig) suksesvol is, byvoorbeeld met verskillende motiewe geassosieer te kan word. Brousseau en Driver (1994) noem dat verskeie studies getoon het dat die sleutelmotiewe in Tabel 1 konsekwent met dieselfde loopbaanpatrone geassosieer is. Vervolgens word na hierdie motiewe as die onderskeie loopbaanpatroonmotiewe verwys.

Tabel 1 toon dat individue met lineêre loopbaanpatroonoriëntasies, mag en prestasie as die belangrikste motiewe ag, terwyl persone met 'n sterk deskundige loopbaanoriëntasie, geleenthede om vaardighede te verbeter en sekuriteit (stabiele werk-
TABEL 1

LOOPBAANPATROONMOTIEWE

\begin{tabular}{lllll} 
& LINEÊR & $\begin{array}{c}\text { DES- } \\
\text { KUNDIG }\end{array}$ & \multicolumn{1}{c}{$\begin{array}{c}\text { SPIRAAL- } \\
\text { VORMIG }\end{array}$} & \multicolumn{1}{c}{$\begin{array}{c}\text { KORT- } \\
\text { STONDIG }\end{array}$} \\
\cline { 2 - 5 } $\begin{array}{l}\text { Sleutel- } \\
\text { motiewe }\end{array}$ & Mag & Kundigheid & Persoonlike groei & $\begin{array}{l}\text { Verskeidenheid } \\
\text { Onafhanklikheid } \\
\end{array}$ \\
& Prestasie & Sekuriteit & Kreatiwiteit & \begin{tabular}{l} 
Mensebetrokkenheid \\
\hline
\end{tabular} \\
\hline
\end{tabular}

situasie) as belangrikste motiewe ag. Pesone met spiraalvormige loopbaanoriëntasies heg die meeste waarde aan persoonlike groei en kreatiwiteit, en dié met kortstondige loopbaanoriëntasies slaan verskeidenheid, onafhanklikheid en mensebetrokkenheid hoog aan.

Brousseau en Driver (1994) noem dat 'n swak passing tussen individue se voorkeur vir die verskillende loopbaanpatrone (lineêr, spiraalvormig, ens.) en die ooreenstemmende motiewe redelik algemeen is (Brousseau \& Driver, 1994). Die loopbaanpatroon wat ' $n$ individu verkies, is dikwels ' $n$ weerspieëling van hoe aantreklik die verskillende patrone binne 'n organisasie se loopbaankultuur is, terwyl die motiewe' $n$ aanduiding is van die tipe loopbaangeleenthede wat werknemers waarlik begeer. So kan 'n individu byvoorbeeld die lineêre loopbaanpatroon verkies, maar die deskundige motiewe hoog aanslaan. Die implikasie hiervan is dat dit onwaarskynlik is dat dié betrokke individue algehele loopbaantevredenheid sal ervaar. 'n Loopbaanpad kan dus op grond van sosiale norme vir 'n individu aanloklik lyk, maar dit sal nie noodwendig sy of haar motiewe en behoeftes bevredig nie.

In hierdie studie word eerstens bepaal of daar ' $n$ passing is tussen die loopbaanpatrone (lineêr, deskundig, spiraalvormig en kortstondig) waaraan individue voorkeur gee en hul ooreenstemmende motiewe. Dan is gepoog om te bepaal in watter mate dié motiewe verskillend manifesteer by dié respondente met 'n passing tussen die loopbaanpatroon waaraan hulle voorkeur gee en die ooreenstemmende motiewe (passingsgroep), en die respondente waar daar nie 'n passing was nie (niepassingsgroep).

Die doel van hierdie studie is om:

- te bepaal in watter mate daar 'n passing is tussen die verskillende loopbaanpatrone waaraan die respondente voorkeur gee en hul ooreenstemmende motiewe; en

- te bepaal of die motiewe verskillend manifesteer by die respondente met 'n passing tussen die loopbaanpatrone waaraan hulle voorkeur gee en die ooreenstemmende motiewe (passingsgroep), en dié respondente waar daar nie 'n passing was nie (niepassingsgroep).

\section{METODE}

\section{Steekproef}

Altesaam 188 bestuurders by verskillende organisasies in Gauteng is betrek. Tabel 2 toon die frekwensie van die totale groep met betrekking tot die verskillende posvlakke en ander biografiese veranderlikes. Alle proefpersone besit minstens Standerd Tien en het die vraelyste volgens eie taalvoorkeur voltooi. Ten einde die kontaminerende effek van heterogeniteit binne steekproewe te vermy, is slegs blanke bestuurders by die steekproef ingesluit.

Volgens hierdie tabel behoort $80,3 \%$ tot die middel- en senior bestuursgroep. Ander belangrike kenmerke van die streekproef is soos volg: $84,2 \%$ was manlik, $70,7 \%$ werk drie jaar of langer vir sy/haar organisasie, $32 \%$ het geen werkveranderings die afgelope tien jaar gemaak nie, en $24 \%$ het slegs een verandering gemaak. Die gemiddelde ouderdom was 38 jaar.

\section{Meetinstrumente}

\section{- Die Biografiese Vraelys}

Die vraelys is saamgestel met die doel om persoonlike inligting te bekom wat nodig is om die steekproef te kon beskryf. 
TABEL 2

FREKWENSIETABEL VAN DIE STEEKPROEF MET BETREKKING TOT VERSKEIE BIOGRAFIESE VERANDERLIKES

\begin{tabular}{ccc}
\hline POSVLAK & AANTAL & PERSENTASIE \\
\hline Senior bestuur & 59 & 31,4 \\
Middelbestuur & 92 & 48,9 \\
Junior bestuur & 37 & 19,7 \\
\hline GESLAG & AANTAL & PERSENTASIE \\
\hline Manlik & 160 & 87,9 \\
Vroulik & 22 & 12,1 \\
\hline JARE DIENS BY & AANTAL & PERSENTASIE \\
ORGANISASIE & & \\
\hline 1 jaar of minder & 11 & 5,8 \\
1-5 jaar & 45 & 23,8 \\
5-10 jaar & 49 & 25,9 \\
10-15 jaar & 38 & 20,1 \\
meer as 15 jaar & 46 & 24,3 \\
\hline AANTAL WERK- & AANTAL & PERSENTASIE \\
VERANDERINGS & & \\
(binne afgelope 10 jaar) & & 32,6 \\
\hline Geen werkverandering & 61 & 19,8 \\
1 werkverandering & 47 & 12,8 \\
2 werkveranderings & 37 & 3,9 \\
3 werkveranderings & 24 & \\
4 werkveranderings & 11 & \\
5 of meer werkveranderings & 7 & \\
\hline
\end{tabular}

- Die Career Concept Questionnaire (CCQ)

Die Career Concept Questionnaire (CCQ) van Driver, Brousseau, Von Glinow \& Prince (1980) is gebruik. Die vraelys meet individue se voorkeur vir sekere loopbaanpatrone (lineêr, spiraalvormig, deskundig, kortstondig) asook die belangrikheid van sekere besluitnemingsfaktore (motiewe) by loopbaankeuses. Twee stelle inligting word met die vraelys bekom. Eerstens, die loopbaanpatroontelling wat' $n$ aanduiding van die respondent se voorkeur vir elk van die verskillende loopbaanpatrone is. Hierdie telling toon gewoonlik hoe sosiaal aantreklik elk van die loopbaanpatrone binne die kultuur van die organisasie is. Die motieftelling illustreer die belangrikheid van die persoonlike motiewe in Tabel 1 vir die individu, wat ' $n$ aanduiding is van die loopbaanpatroon wat die individu eintlik sou wou hê.

Die betroubaarheid en geldigheid van die CCQ is deur Coombs (1989) ondersoek. Positiewe korrelasies is met die toets-hertoetsmetode gevind. Wat geldigheid betref bevestig die navorsing 'n passing of konstrukgeldigheid tussen die basiese beskrywings van die loopbaanpatrone en die sleutelelemente van die patrone. Oor die algemeen bevestig die resultate die bruikbaarheid van die vraelys om die individuele loopbaanpatrone asook die verband tussen die patrone en die loopbaanmotiewe (besluitnemingsfaktore) te identifiseer. Die vraelys toon dus potensiaal vir suksesvolle toepassing onder Suid-Afrikaanse omstandighede.

Die vraelyste is by sewe organisasies versprei. 'n Brief wat die doel van die ondersoek beskryf en anonimiteit gewaarborg het, is by die vraelys ingesluit. Met die ondersteuning van 'n kontakpersoon by elk van die organisasies is terugvoering van $64 \%$ gekry. Die kontakpersone was onafhanklik en nie die onmiddellike hoof van die proefpersone nie, en hulle funksie was hoofsaaklik om die proefpersone aan te moedig om die vraelyste te voltooi.

\section{Statistiese metodes}

Die passing tussen loopbaanmotiewe en -voorkeure is van frekwensieontledings afgelei. Om die manifestasie van motiewe te ondersoek, is daar 'n strukturele ontleding van die gemanifesteerde loopbaanmotiewe binne die twee groepe uitgevoer. Die Lisrel VIII program (Jöreskog \& Sörbom, 1993) is vir die doeleindes gebruik. Dit is ' $n$ waardevolle statistiese tegniek om data met metingsfoute te ontleed en te kontroleer.

\section{RESULTATE}

Om te bepaal in watter mate daar' $n$ passing is tussen die loopbaanpatroon waaraan respondente voorkeur gee en hul ooreenstemmende motiewe, soos deur die CCQ gemeet, is frekwensies bereken.

TABEL 3

LOOPBAANPATROON- EN LOOPBAANMOTIEFFREKWENSIES Loopbaanmotiewe

\begin{tabular}{|c|c|c|c|c|c|}
\hline $\begin{array}{l}\text { Loopbaan- } \\
\text { patroon- } \\
\text { voorkeure }\end{array}$ & Lineêr & Deskundig & $\begin{array}{l}\text { Spiraal- } \\
\text { vormig }\end{array}$ & $\begin{array}{c}\text { Kort- } \\
\text { stondig }\end{array}$ & \\
\hline Lineêr & 20 & 13 & 24 & 17 & $\begin{array}{c}74 \\
39,4 \%\end{array}$ \\
\hline $\begin{array}{c}\text { Des- } \\
\text { kundig }\end{array}$ & 3 & 14 & 5 & 2 & $\begin{array}{c}24 \\
12,8 \%\end{array}$ \\
\hline $\begin{array}{l}\text { Spiraal- } \\
\text { vormig }\end{array}$ & 21 & 18 & 27 & 19 & $\begin{array}{c}85 \\
45,2 \%\end{array}$ \\
\hline \multirow[t]{2}{*}{$\begin{array}{l}\text { Kort- } \\
\text { stondig }\end{array}$} & 3 & 0 & 1 & 1 & $\begin{array}{c}5 \\
2,7 \%\end{array}$ \\
\hline & $\begin{array}{c}47 \\
25,0 \%\end{array}$ & $\begin{array}{c}45 \\
23,9 \%\end{array}$ & $\begin{array}{c}57 \\
30,3 \%\end{array}$ & $\begin{array}{c}39 \\
20,7 \%\end{array}$ & 188 \\
\hline
\end{tabular}

Tabel 3 is ' $n$ matriks wat die frekwensies van loopbaanpatrone en -motiewe vir 188 bestuurders aandui. Die horisontale as dui daardie respondente aan wat elk van die vier loopbaanpatrone die hoogste beoordeel het. Byvoorbeeld 85 (of $45,2 \%$ van die steekproef) het aangedui dat hulle die spiraalvormige loopbaanpatroon verkies en 74 of $39,4 \%$ die lineêre patroon. Die totale van die vertikale asse dui aan hoe die respondente die motiewe beoordeel het. Byvoorbeeld 57 (of 30,3\% van die steekproef) het die spiraalvormige motiewe (persoonlike groei en kreatiwiteit) die hoogste beoordeel, terwyl 47 of $23,9 \%$ die lineêre motiewe (mag en prestasie) die hoogste beoordeel het.

Die verskille met betrekking tot die loopbaanpatrone en die motiewe is opvallend (sien Tabel 3). Die meeste respondente $(45,2 \%)$ gee voorkeur aan die spiraalvormige loopbaanpatroon. Daarna volg die lineêre patroon, met $39,4 \%$ respondente. Hierdie twee groepe verteenwoordig saam $85 \%$ van die steekproef. Wat die motiewe betref, word ' $n$ heeltemal ander tendens opgemerk. Die verspreiding is hier meer gelyk, met bykans dieselfde aantal respondente wat die verskillende motiewe kies. Volgens die resultate is daar 'n swak passing tussen die loopbaanpatrone waaraan die respondente voorkeur gee en die ooreenstemmende motiewe, of daardie faktore wat belangrik by die neem van loopbaanbesluite is. Hoewel $45 \%$ van die steekproef die spiraalvormige patroon verkies, ag slegs $30 \%$ die spiraalvormige motiewe as belangrik. Dieselfde geld ook vir die lineêre patroon, waar 39\% van die steekproef dié patroon verkies, terwyl net $25 \%$ die lineêre motiewe as belangrik aanslaan. Dit beteken dat ' $n$ aantal individue wat byvoorbeeld die lineêre patroon (opwaartse beweging) verkies, se motiewe en behoeftes waarskynlik beter by die ander patrone pas.

Wat die totale groep betref is daar slegs by een derde van die respondente 'n passing tussen die loopbaanpatroon wat hulle verkies en die ooreenstemmende motiewe gevind. Die implikasie hiervan is dat ongeveer twee derdes van die steekproef se loopbane nie volgens hulle spesifieke behoeftes en motiewe gerig is nie. Ofskoon hierdie individue voel dat hulle 'n hoë gehalte loopbaan volg, bestaan daar waarskynlik ontevredenheid met die inhoud daarvan. 
Die ondersoek van Brousseau en Driver (1994) het soortgelyke resultate opgelewer. Vyf en vyftig persent van die respondente in hulle ondersoek het die lineêre patroon verkies en $43 \%$ die spiraalvormige patroon. Slegs $6 \%$ het die deskundige patroon en $5 \%$ die kortstondige patroon as wenslik beskou. Die verspreiding van die motiewe was ook meer gelyk. Slegs $28 \%$ van die proefgroep het die lineêre motiewe as belangrik beskou, terwyl $27 \%$ die spiraalvormige motiewe as belangrik geëvalueer het, $24 \%$ die deskundige motiewe en $20 \%$ die kortstondige motiewe. Die resultate dui ook op 'n onbevredigende passing. Wat die totale groep betref, was daar ook by slegs een derde van die respondente ' $n$ passing tussen die loopbaanpatrone en die ooreenstemmende motiewe.

Die mate waarin respondente met 'n passing tussen die loopbaanpatroon wat hulle verkies en die ooreenstemmende motiewe (passingsgroep) verskil van die respondente wat nie 'n sodanige passing het nie (niepassingsgroep), ten opsigte van die manifestasie van die loopbaanmotiewe, is ook bepaal.

Die aanname is gemaak dat die parameterskattings van die twee groepe verskil, maar dat die bronne van foutvariansie (na aanleiding van metingsfoute en eksogene veranderlikes) vir beide groepe dieselfde is. ' $n$ Passingskriterium van 0,001 is na ses iterasies bereik. Lisrel bied ook verskillende passingstatistiek, en daarvolgens is 'n goeie passing gevind tussen die teoretiese model en die data wat in die studie gebruik is (RMSEA $<0,05$ ). stemmende motiewe moet wees. Die resultate van hierdie studie dui oor die algemeen op 'n swak passing. Dit impliseer dat talle bestuurders bes moontlik 'n lae gehalte werklewe ervaar, deurdat dit wat hulle werklik in hulle loopbane motiveer, nie 'n rol speel nie. Die feit dat 'n groot aantal respondente die spiraalvormige patroon verkies is bemoedigend, aangesien sodanige individue geneig is om beter in veranderende organisasies aan te pas en te vorder. Die groot presentasie respondente wat lineêre patrone verkies, is kommerwekkend. Bestuursvlakke raak minder en veral middelbestuurders verloor hulle werk. Dit bring mee dat opwaartse beweging in die hiërargiese struktuur nie meer so vrylik voorkom nie. Sodanige individue behoort dus van hulle werklike motiewe bewus gemaak te word en aangemoedig te word om ' $n$ ooreenstemmende loopbaanpad te volg. In ' $n$ vinnig veranderende werkomgewing is selfkennis met die oog op ' $n$ beter beroepspassing belangriker as ooit. Om ingeligte keuses te kan maak en deurdagte loopbaanbeplanning te kan doen moet persone 'n konseptuele raamwerk kry waarvolgens hulle kan sien hoe hulle visie van loopbaansukses en persoonlike motiewe verbind kan word met verskeie loopbaanmoontlikhede. Te midde van snel veranderende omstandighede wat ook die loopbaankeuses van mense beïnvloed, sou die model veral van nut kon wees om individue se loopbane volgens spesifieke behoeftes en motiewe te rig.

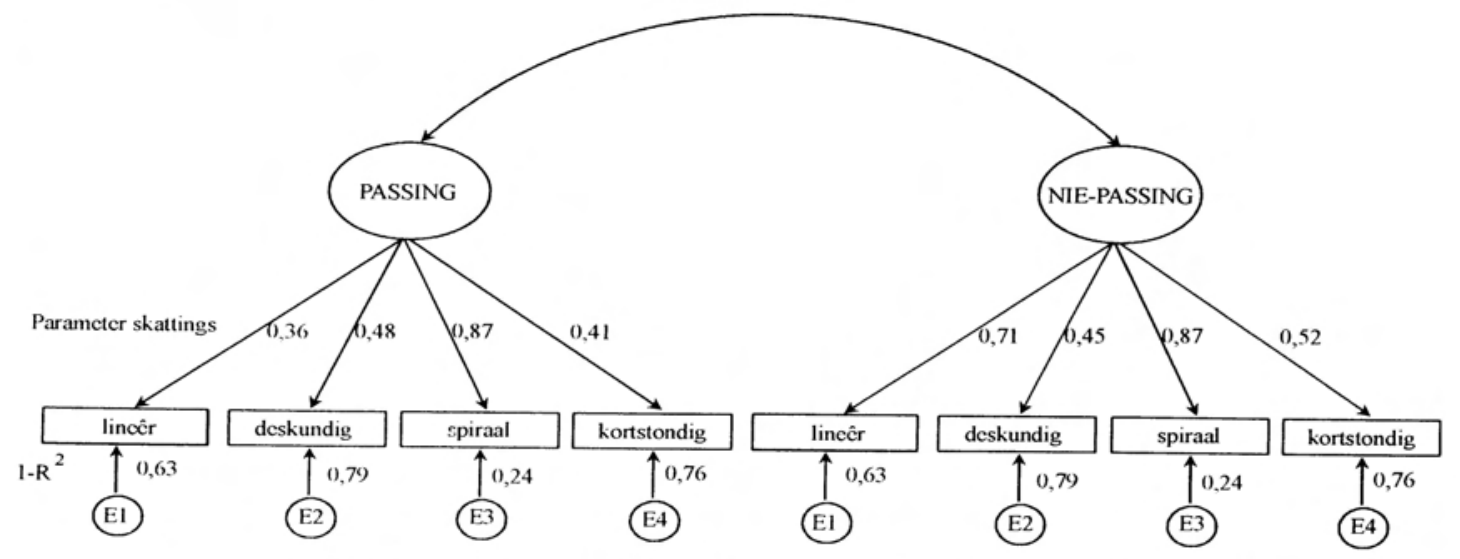

Figuur 1: Manifestasie van loopbaanmotiewe by passings en nie-passingsgroepe.

Van die gemanifesteerde loopbaanmotiewe by die passings- en niepassingsgroep toon die lineêre motief die grootste verskil tussen die groepe. By die niepassingsgroep manifesteer die lineêre motief heelwat sterker (parameterskatting $=0,71$ ) as by die passingsgroep (parameterskatting $=0,36$ ). Van die motiewe wat gemeet is, is dit merkwaardig dat hierdie motief juis die swakste manifesteer by die passingsgroep. Dit wil dan voorkom asof hierdie motief die grootste oorsaak van 'n gebrek aan passing tussen loopbaanpatroonmotiewe en die beroepslewe is. Brousseau en Driver (1994) het in hulle ondersoek 'n swak passing tussen veral die lineêre loopbaanpatroon en lineêre motiewe gevind, waar die respondente veral die lineêre loopbaanpatroon verkies het, maar die lineêre motiewe laag aangeslaan het. Die bevindings van hierdie studie stem hiermee ooreen aangesien die diskrepansie tussen lineêre motiewe en lineêre patrone die grootste by die niepassingsgroep is.

Dit is ook merkwaardig dat die kortstondige loopbaanmotiewe hoër by die niepassingsgroep manifesteer. Dit wil dus voorkom asof die bydraende effek van hierdie motiewe tot niepassings, nie buite rekening gelaat kan word nie.

\section{GEVOLGTREKKINGS}

Die ideaal is immers dat daar 'n passing tussen die loopbaanpatroon waaraan individue voorkeur gee en hul ooreen-

\section{VERWYSINGS}

Brousseau, K.R. (1990). Career dynamics in the baby boom and baby bust era. Journal of Organizational Change Management, 3 (3), 46-58.

Brousseau, K.R. \& Driver, M.J. (1994). Enhancing informed choice: A career-concepts approach to career advisement. The Magazine of the Graduate Management Admission Council, Spring, 24-31.

Cascio, W.F. (1995a). Guide to responsible restructuring. Washington: US Department of Labor: Office of the American workplace.

Cascio, W.F. (1995b). Whither industrial and organizational psychology in a changing world of work. American Psychologist, 50(11), 928-939.

Coombs, M. (1989). Measuring career concepts: An examination of the concepts, constructs and validity of the CCQ. Unpublished PhD Dissertation: University of Southern California, Los Angeles.

Davis, D.D. (1995). Form, function, and strategy in boundaryless organizations. In: A. Howard (Ed.), The changing nature of work (p. 117-134). San Francisco: Jossey-Bass.

Driver, M.J., Brousseau, K.R., Von Glinow, M.A. \& Prince, J.B. (1980). The career concept questionnaire. Department of Management and Organization. University of Southern California, Los Angeles. 
Drucker, P.F. (1988, Jan/Feb). The coming of the new organisation. Harvard Business Review, 45-53.

Emigrasie lei tot ' $n$ tekort aan bestuurslede (22 Januarie 1996). Sake-Beeld, p 51.

Hall, D.T. \& Mirvis, P.H. (1995). Careers as lifelong learning. In: A. Howard (Ed.), The changing nature of work (pp. 323-358). San Francisco: Jossey-Bass Publishers, 323-358.

Handy, C. (1990). The age of unreason: A new renaissance? Soundview Executive Book Summaries, 12(1), 1-8.

Handy, C. (1995). Beyond certainty: The changing worlds of organisations. London: Hutchinson.

Harris, T.G. (1993 May/June). The post-capitalist executive: An interview with Peter F. Drucker. Harvard Business Review, 115-122.

Jöreskog, K.G. \& Sörbom, D. (1993). Lisrel 8: Structural equation modeling with the SIMPLIS Command language. Chicago: Scientific Software.

Kanter, R.M. (1990). When giants learn to dance. New York: Simon \& Schuster.

Large drop in staff levels at local companies. (Sept/Oct., 1994). CSD Bulletin 1(6), 5.

Mastrantonis, H. \& Nel, C. (1995). The move towards democracy at work. People Dynamics, 13(3), 18-22.

Noe, R.A., Hollenbeck, J.R., Gerhart, B. \& Wright, P.M. (1994). Human resource management: Gaining a competitive advantage. Illinois: Irwin.

Noer, D. (1993). Four new realities. Executive Excellence, 2, 16-17.

Sadie, J.L. \& Martins, J.H. (1994). Projections of the South African Labour Force 1991-2011. Pretoria: Bureau of Market Research; University of South Africa.

Sadler, P. (1991). Designing organisations. London: Mercury Books.

Schein, E.H. (1993). Career survival: Strategic job and role planning. San Diego: Pfeiffer \& Company.

Senge, P.M. (1990). The fifth principle: The art and practice of the learning organization. London: Century Business.

Uys, J.S. (1993). The organisation of the future. Paper presented at SAIBI Congress, Grahamstown. 